\title{
Individual and Institutional Determinants of the Scientific Production of Academic Staff in Human and Social Sciences in Moroccan Universities
}

\author{
Doukkali Sanaa
}

Laboratory of Social Sciences, Faculty of Law, Economics and Social Sciences, Hassan II University of Casablanca, Morocco

\section{ARTICLE INFO}

\section{Keywords:}

Academic Staff

Morocco

Research

Scientific Productivity

Social and Human Sciences

\begin{abstract}
This research focuses on the scientific production of academic staff in Human and Social Sciences (HSS) in Moroccan universities. It takes place in a context marked by strong pressures related to scientific research and by changes in the mission of the University that impact the work of the academic at all levels. With regard to HSS, the Moroccan university system appears to be far from being in line with the logic of global competition, and the research activity of the academic staff in HSS is often out of step with institutional policies and the needs of national and international evaluation systems. This can be seen from the publication figures reported in commissioned reports or expert assessments carried out by national or international organizations, or by the scarcity of work that has studied the determinants of the production of academic staff in HSS in Morocco. Hence the objective of this research is to formulate a research model that gathers the potential determinants of the level of scientific production of academic staff and that is adapted to the context of Moroccan universities. Our research therefore aims to fill certain gaps in the knowledge of the social dynamics of knowledge production practices by HSS researchers who are often confused with their colleagues in other scientific fields.
\end{abstract}

\section{Introduction}

The question of the development of scientific research today occupies all academic institutions in the world and concerns all disciplines of knowledge. To this end, universities and academics are constantly called upon to improve their position in evaluation systems that attempt to assess research activity, particularly through the scientific production of academic staff. Considered as the most tangible result of their research activity, scientific production is one of the main measures for the calculation of university rankings and an essential indicator for the evaluation of researchers and the structures to which they are attached. However, these predominantly quantitative evaluation systems, initially planned for the natural and technical sciences and based essentially on their publications, and therefore on the ranking of journals, are inspired by the Anglo-Saxon model and by a broader international dynamic, where the HSS, especially local HSS, has difficulty finding its place.

Moreover, in developing countries, and more particularly in the Arab region, of which Morocco is a part, the massification of education since the 1980s has meant that universities have not given SHS research a place that would allow it to reach the desired level, the emphasis and

* Corresponding Author E-Mail Address: sanaadoukkali@gmail.com 
budgets being mainly focused on the training of an education system capable of absorbing student numbers and training administrative and technical staff. Globalization and its insistent calls to integrate a knowledge economy have only contributed to the depreciation of the place of the SHS in favor of research serving the needs of the market economy (Hanafi, Sari. \& Arvanitis, Rigas, 2014). Added to this is the growing intervention of international organizations in development policies, which has given a significant number of university researchers the opportunity to become local experts in a "market" for intellectual services (Granier et al., 2018), thus positioning themselves beyond the field of university scientific research, which leads them to oscillate between two statuses: that of the scientist (subject to the strict rules of scientific production) and that of the expert who must provide a service that corresponds as closely as possible to the expectations of the applicant.

Moreover, beyond the orientations dictated by the influence of political and economic fields, which mark important local disparities that shape the research ecosystem and impact the level of scientific production, evaluations often ignore the conditions under which academic staff produce their research. The scientific field is a social space where the institutional and organizational conditions of the work of academic staff play an important role in the process of scientific production. This importance can be strongly grasped when one wishes to account for the multidimensional nature of the work of academic staff, which is reflected in the new missions of the University. Between the competing demands of teaching, research, administrative or managerial responsibilities, services, and the numerous activities that fall under each of these missions, in addition to other professional activities in which he or she is required to participate in the framework of collective life, the teacher-researcher is forced to make choices that translate into career strategies, all the more so as the threshold of demand for these activities is tending to rise. These strategies depend on the position occupied by the teacher-researcher in the social structure of the university space, his or her expectations and objectives in relation to this space, the forms of capital and power at his or her disposal, the resources to which he or she has access (institutional and collegial support) and the mode of governance of the institution.

While the institutional context clearly has a strong influence on faculty engagement in research activities, it is also clear that there are considerable individual differences in the way academics act and interact in this context. The literature review shows that factors such as age, gender, discipline, family responsibilities, doctoral period, research interest and career satisfaction all influence scientific output (Fox \& Mohapatra, 2007).

The literature reports a significant amount of work that has examined the question of the determinants of the scientific production of academic staff. To date, the majority of the published studies have focused on the academic community in developed countries. In many parts of the world, this apparently important research does not seem to have received the attention it deserves. (Long et al., 1998) argue that such studies conducted in one country are not necessarily valid (or applicable) to other regions of the world, particularly those in developing countries. This assertion is based on the idea that academic institutions in different parts of the world have unique environmental characteristics (in terms of culture, organizational structure, governance, etc.); furthermore and in terms of disciplines, the output of research in the social humanities and social sciences has been less often considered, while in developing countries it is rarely examined (Gaillard, 1987); (Gaillard, 1989).

From the early 2000s, Morocco has undertaken evaluations of its research system. The first bibliometric studies that took stock of the 1990s showed that Morocco has experienced a considerable rise in power, raising it to the third largest science-producing country in Africa. However, from 2000 onwards, a shift in direction emerged and the pace of growth slowed down. An external evaluation conducted between 2001 and 2003 by European scientists was also used. 
The results of this evaluation concluded that the country had a rich potential of researchers and that the support measures promoted by the Ministry of Research were well oriented. Nevertheless, the system was at a crossroads. Without a new driver for research, momentum could be lost and investment could be lost (Pier Luigi Rossi \& Roland Waast, 2008).

The bibliometric study conducted on Morocco's scientific production between 1995 and 2006 by Roland Waast, showed a shift in the generalized scientific production. Several disciplines that had experienced a boom were entering a less productive phase without a new generation of researchers. However, the bibliometric approach was not sufficient to explain this decline. "A sociological approach based on a field survey of actors, concerning their strategies, motivations, and research approach, in their academic context, should provide complementary elements of understanding" (Waast et al., 2007). "The causes of this slowdown are still poorly understood; an interpretation in terms of generational and institutional change - very common in Morocco - is insufficient. Moreover, the ministerial reform of universities, which largely took place after the evaluation, has still not satisfactorily resolved the question of the place of research" (Kleiche-Dray et al., 2008).

These concerns are confirmed by the conclusions of the study conducted in August 2010 by IMIST (Moroccan Institute of Scientific and Technical Information), which show that between 1999 and 2010, the national scientific production of Universities reached nearly 19372 publications, of which only $2.39 \%$ were in SHS. This production is unevenly distributed among universities.

However, the main study that assessed the scientific production of researchers in the field of Human and Social Sciences remains the one conducted by Mohamed Cherkaoui between 2005 and 2009, which focused in the first part on a study of the morphology of the faculty, its social representation and the notion of scientific community. In a second part, Mohamed Cherkaoui conducted a bibliometric study of the production of academic staff in the SHS from 1956 to 2006, mapping this production and defining its trends and orientations. The main results of this study assume that the morphology and functions of the teaching profession are the result of an adaptive process between public policies and individual decisions, and that, in addition to public policies, teacher choices depend on a triangular causal structure composed of three sets of variables: social selection, the system of social representations of the teacher, and finally the markets to which the teacher is directed. They note, however, an absence of structuring of disciplinary fields and the emergence of a scientific community, and little competition since the criteria for recruitment and promotion leave no room for effort and emulation. The results also suggest that academic staff do not make science their full-time vocation and that HSS as practiced by Moroccan researchers tends to become cameral sciences (Cherkaoui, 2011)

These studies, conducted through internal evaluations or external expertise, all concluded that research in the humanities and social sciences in Morocco is generally at a low level and is out of step with global competition. Figures corresponding to the production of Moroccan researchers in SHS in the WOS (Web of Science) corroborate these findings: Moroccan researchers published between 2015 and 2019 1,239 publications indexed in the Web of Science in SHS, which represents a share of $0.06 \%$ compared to the world production in these fields. These publications have a standardized citation impact per category of 0.83 (the world average is 1). These same publications have accumulated 2,150 citations. A percentage of $32.4 \%$ of these publications were cited at least once.

The evaluations also agree on the idea that studies devoted to public policies in teaching and research and those that are purely bibliometric are not sufficient to explain current trends in the scientific production of academic staff in the SHS. They recommend that sociological studies be conducted among academic staff in order to understand the reality of the exercise of research activity and scientific production by academic staff themselves. 
Table 1.

SHS publications in the WOS

\begin{tabular}{lccccc}
\hline Country & $\begin{array}{c}\text { Numbers of } \\
\text { Documents }\end{array}$ & $\begin{array}{c}\text { Global } \\
\text { Contribution }\end{array}$ & $\begin{array}{c}\text { Standardized } \\
\text { Citation Impact }\end{array}$ & $\begin{array}{c}\text { Cited } \\
\text { Number }\end{array}$ & $\begin{array}{c}\text { Cited } \\
\text { Docs }\end{array}$ \\
\hline World & $2,226,594$ & & 0.92 & $4,288,808$ & 33.7 \\
EGYPT & 2,550 & $0.11 \%$ & 1.01 & 5,682 & 42.9 \\
TUNISIA & 1,800 & $0.08 \%$ & 0.95 & 4,772 & 46.8 \\
MOROCCO & $\mathbf{1 , 2 3 9}$ & $\mathbf{0 . 0 6 \%}$ & $\mathbf{0 . 8 3}$ & $\mathbf{2 , 1 5 0}$ & $\mathbf{3 2 . 4}$ \\
ALGERIA & 745 & $0.03 \%$ & 0.98 & 1,504 & 41.3 \\
\hline
\end{tabular}

Exported date 2020-04-27. InCites dataset updated Mar 26, 2020.

Includes Web of Science content indexed through Feb 29, 2020

Given the recent reforms of the higher education and research system and the importance given to the evaluation of research in all fields of knowledge, as well as the growing interest in the human and social sciences, which is highlighted and reinforced by developments in Morocco and in light of global developments at the political, economic, and social levels, studies on the factors that impact the level of scientific production of Moroccan academic staff in the human and social sciences seem well justified.

The present research is in line with this objective. We wish to study the determinants of the scientific production of academic staff in the Humanities and Social Sciences in the context of Moroccan universities, arguing that the different positions that reflect a higher or lower level of scientific production result from the combination of the individual characteristics of academic staff and their perception of institutional characteristics.

In this work, we have tried to formulate a conceptual model of the factors likely to impact the level of scientific production of academic staff. This was done on the basis of a review of both theoretical and empirical literature.

Thus, and in continuity with the work of Blackburn and Lawrence (1995), we have analysed these factors from two perspectives: institutional, linked to the working environment of academic staff, and individual, linked to the profile of academic staff.

\section{Materials and Methods}

The method we used to build our model consisted of a review of the main conceptual models that attempted to study the determinants of the scientific production of faculty. The scientific production of academic staff has been studied for several decades. The factors likely to influence this production are multiple and the literature reports numerous studies that attempt to present these factors, to explain their involvement in the variation of scientific production, by grouping them into clusters or models. We present here the best-known models and those most often used in the literature.

\subsection{Fox's Model}

The first model that attempted to aggregate the determinants of production into one model was presented by (Fox, 1983). He distinguished between individual-level variables, environmental variables and feedback processes. The first group includes motivation, innate interest in research, cognitive style, research-related abilities, work habits and age of faculty. Environmental variables that are positively correlated with output include graduate education, prestige of the department, the degree of involvement within the unit, and the degree of freedom the unit provides to pursue individual interests. 
Fox also studied feedback processes using reinforcement and cumulative advantage theories. He thus suggests that there is a cyclical process linking individual and environmental variables, such that early productivity leads to certain benefits, and that these benefits provide access to certain resources that in turn lead to greater benefits and an increasing rate of productivity (Fox, 1983).

\subsection{Finkelstein's Model}

The model suggested by (Finkelstein, 1984) used social data and data from scientific research carried out by American professors to identify seven variables that determine the level of scientific production of academic staff. These variables include: the researcher's research orientation, the highest degree in his or her field of study, early career publishing habits, previous publishing activities, communication with colleagues in the discipline, publications in a large number of journals, and sufficient time allocated to research.

According to (Bland et al., 2005), this model has been very useful in uncovering individual determinants that may influence the scientific output of faculty. However, according to (Creswell, 1985), the model did not incorporate institutional or environmental characteristics that could affect faculty research productivity.

\subsection{Creswell's Model}

Creswell studied the sociology of science and was able to use sociological data from researchers to draw up the institutional characteristics that affect the scientific production of the teacher-researcher (Creswell, 1985). Creswell's model goes beyond individual characteristics by recognizing that faculty researchers are more productive when they work in a large university that rewards research and allows sufficient time for faculty to conduct their research. According to (Bland et al., 2005) this model states that the productive environment has a significant effect on research output.

Creswell described the most productive researchers as those who tend to work in research projects where research has been rewarded and faculty have had sufficient time to conduct research. They were also those who were able to hold a high professional standing, completed their $\mathrm{PhD}$ and devoted the majority of their time to research activities (one-third of the time), published early in their careers, received positive feedback from their peers, and collaborated with colleagues inside and outside their institution on the topics of their research.

Thus, Creswell's model recognizes the importance of institutional data and the research culture within the institution on the scientific output of faculty. However, Creswell noted that the relationship between individual variables and environmental variables is still not clear. $\mathrm{He}$ suggested that "researchers might consider using degree, discipline, institutional affiliation, and career age as control variables in a model and closely examine the significant productivity factors that are related to the teacher-researcher's work environment" (Creswell, 1985).

\subsection{The Dundar and Lewis Model}

Dundar and Lewis used a study at 274 universities in the United States where they studied 3,600 research and doctoral programs to propose a model in which the scientific output of faculty is primarily related to personal characteristics and individual experiences in the work environment on the one hand, and institutional and departmental factors that include leadership, culture, structure and policy variables on the other (Halil Dundar \& Darrell R. Lewis, 1998). The results indicate that the size of faculty groups associated with the field of study is one of the major contributors to the scientific output of faculty. Other elements were also identified as having an impact on faculty scientific production, such as being a private rather than a public institution, having a larger number of full professors and having a larger percentage of faculty in a department who actively publish in peer-reviewed journals. 


\subsection{Bland's Model}

One of the most widely used theoretical models for the study of scientific production is Bland's model (Bland et al., 2005), which was tested in the context of a large medical school and resulted in the publication of their book "The Research-Productive Department: Strategies from Departments That Excel". In their model, the authors first introduced the interesting idea that a researcher's scientific production was based on three foundations: personal characteristics, characteristics of the home institution, and characteristics of the host institution (Bland et al., 2005).

These three foundations are equally divided into three blocks of characteristics: individual, institutional, and leadership - which they consider to be the pillars of faculty members' individual and group (department) scientific production. All three blocks derive their legitimacy from an extensive literature review by Bland and colleagues, which identified elements associated with each block that influence individual and group production. In summary, (Bland et al., 2005) were able to bring together in the same model three groups of individual, institutional and leadership components that function as a whole and are mutually reinforcing.

\subsection{Blackburn's Model}

Blackburn \& Lawrence drew on literature searches of major U.S. research databases over the past three decades to propose a comprehensive framework that brings together the major factors that influence faculty production in both research and teaching (Blackburn \& Lawrence, 1995). In their work, these researchers have mobilized cognitive motivation theory to formulate their explanation within the framework of two essential elements: social knowledge and environmental response. Social knowledge refers to faculty members' perceptions of various aspects of the social life of their work environment (Blackburn \& Lawrence, 1995).. In their model, positive outcomes related to group climate, communication and networks are identified as the most important environmental elements that contribute to productivity. The environmental response (or social response) corresponds to all types of feedback that academic staff receive from their work environment (from colleagues, administrators, scientific or administrative committees, etc.) and which will contribute to the formation of beliefs and perceptions that will in turn play an important role in determining their behaviour.

Their framework also listed four individual constructs: (socio-demographic characteristics, career, self-knowledge and social knowledge) and three environmental constructs (environmental conditions, environmental response and opportunities) as indicators of faculty behaviour.

Their model was also interested in the dynamic interaction between (self-knowledge), which in their view refers to the self-assessment of one's own individual characteristics, and (social knowledge), which refers to the perception of the institutional conditions of research.

Their results suggest that academics assess their personal capacities in different ways and that these assessments interact with their perceptions of the environment to produce variations in activities that lead to higher or lower research results (Blackburn \& Lawrence, 1995). 


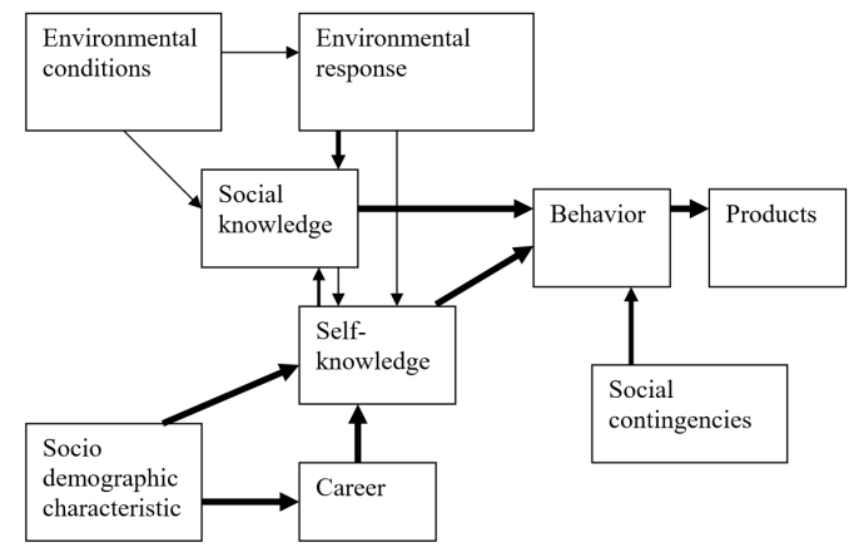

Figure 1. Blackburn and Lawrence Model 1995

- The socio-demographic characteristics were age, race, and gender. Career-related variables included discipline, graduate school attendance, highest degree obtained, place of work, degree, tenure status, career age, publications, and career satisfaction. Self-knowledge variables included interest and preference for a job, commitment, effectiveness (competence and influence), and psychological traits (personality, satisfaction and morale). Social knowledge consisted of faculty members' perceptions of various aspects of their work environment and included social and material supports. Social supports include commitment of colleagues and administrators, committee decisions, faculty meetings, intellectual climate, leadership, institutional rules and standards, professional association practices, while material supports and aids include salary and equipment.

- Environmental conditions are considered to be factors external to the workplace that affect research outcomes. For example, government decisions to fund new areas of research, or to discontinue subsidies for certain research projects, would undoubtedly impact output. Environmental responses can be promotion, tenure, merit increases, administrative support, funding to attend conferences, or even the allocation of a research assistant. Social contingencies relate to family responsibilities or extended sick leave.

\section{Results}

Starting from the conceptual model of Blackburn and Lawrence (1995), and taking into account the specificities of the Moroccan university context, we have established our research model which combines individual and institutional factors:

\subsection{Individual Factors}

To explain the variation in scientific production among academic staff, much of the literature focuses on individual variables, such as demographic characteristics, professional characteristics, personal characteristics, or social contingencies. Demographic data are essential for a good understanding of the social life of faculty members. The role of factors such as age and gender in the variations observed in the scientific production of academic staff will be examined. Professional factors such as degree, field, language of instruction or seniority, and other personal factors related to the doctoral study phase, interest in research, and satisfaction will also be studied. Social contingencies will be approached from two angles: family responsibilities and external activities.

\subsection{Institutional Factors}

Starting from the observation that academic staff with individual characteristics do not exist independently of their environment, and that scientific work is carried out in organizations that operate within the framework of organizational practices and policies, that it requires human 
and material resources, and that it is carried out in work groups characterized by work practices and a work climate, we can then suggest that the perceptions that academic staff develop regarding the characteristics of the institutional environment can either facilitate or limit the scientific production of academic staff. This suggestion is corroborated by (Fox, 1983), who defends the idea that research production is strongly influenced by the social and organizational context in which it takes place (Fox, 1983).

In order to understand the influence of the perception of institutional factors by academic staff on scientific production, we will study the influence of teaching activities, the promotion system, institutional support, collegial support and, finally, governance on scientific production.

In summary, our model is structured around two dimensions:

1- Individual factors, which comprise three constructs:

- Demographic and career factors (age, gender, grade, field, language of instruction, years of experience).

- Personal factors (PhD career path, research interest, job satisfaction)

- Social Contingencies (Family Responsibilities and External Activities)

2- Institutional factors which include:

- Perceptions regarding the exercise of the teaching activity

- Perceptions of the promotions system

- Perceptions of institutional support

- Perceptions of collegial support

- Perceptions of governance

Our research model is therefore as follows:

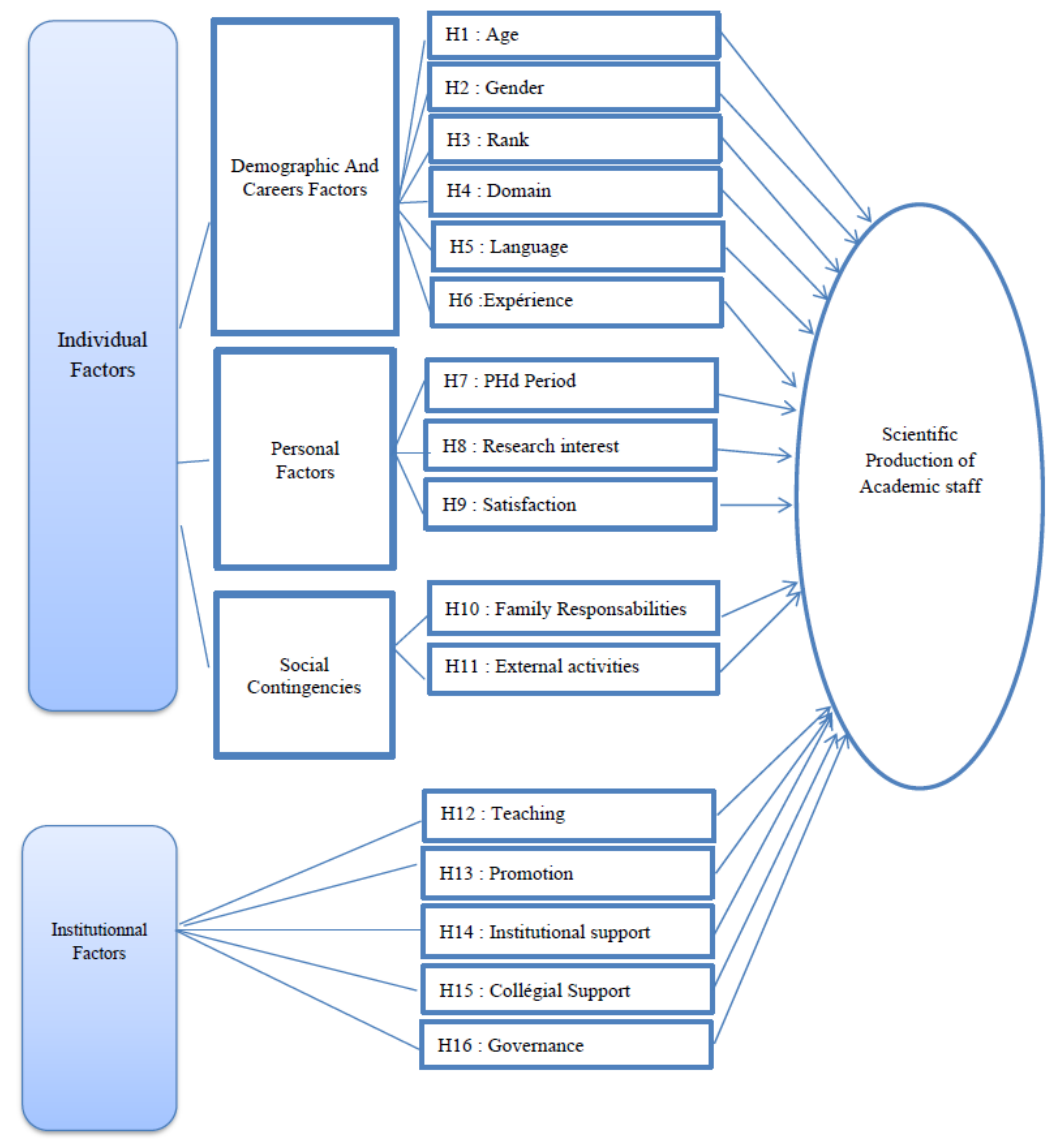

Figure 2. Research model 


\section{Conclusion and Discussion}

In this paper, we proposed a conceptual model of the determinants of the scientific production of academic staff in Moroccan universities. In the same reflection proposed by Blackburn and Lawrence (1995), we have identified the explanatory variables according to individual logic where Demographic and career factors (Age, Gender, Grade, Field, Language of instruction, Years of experience), personal factors ( $\mathrm{PhD}$ career, Interest in research, job satisfaction) and social contingencies (Family responsibilities and external activities) were found to be the main factors. At the institutional level, we raised that the perception of academic staff with regard to teaching activity, the promotion system, institutional support, collegial support and governance inevitably influenced the scientific production of academic staff.

Thus, the next step in our research process is to empirically test the validity of our research model on the basis of a confirmatory quantitative study conducted on a representative sample of SSH academic staff in Morocco.

\section{References}

Blackburn, R. T., \& Lawrence, J. H. (1995). Faculty at Work: Motivation, Expectation, Satisfaction. Johns Hopkins University Press.

Bland, C. J., Center, B. A., Finstad, D. A., Risbey, K. R., \& Staples, J. G. (2005). A theoretical, practical, predictive model of faculty and department research productivity. Academic Medicine: Journal of the Association of American Medical Colleges, 80(3), 225-237.

Cherkaoui, M. (2011). Crise de l'université : Le nouvel esprit académique et la sécularisation de la production intellectuelle. Droz.

Creswell, J. W. (1985). Faculty Research performance: Lessons from the sciences and the social sciences. A.S.H.E.

Finkelstein, M. J. (1984). The American academic profession : A synthesis of social scientific inquiry since World War II. ERIC.

Fox, M. F. (1983). Publication Productivity among Scientists : A Critical Review: Social Studies of Science. https://doi.org/10.1177/030631283013002005

Fox, M. Frank., \& Mohapatra, Sushanta. (2007). Social-Organizational Characteristics of Work and Publication Productivity among Academic Scientists in Doctoral-Granting Departments. The Journal of Higher Education, 78(5), 542-571. https://doi.org/10.1353/jhe.2007.0032

Gaillard, J. (1987). Les chercheurs des pays en développement origines, formations et pratiques de la recherche. Ed. de l'ORSTOM : Institut français de recherche scientifique pour le développement en coopération.

Gaillard, J. (1989). Les chercheurs et l'emergence de communautes scientifiques nationales dans les pays en developpement. CNAM. http://www.theses.fr/1989CNAM0098

Granier, F., Ould-Ferhat, L., \& Thobois, P. (2018). Où en est la demande sociale de sociologie aujourd'hui ? Sociologies pratiques, $N^{\circ} 36(1), 1-8$.

Halil Dundar, \& Darrell R. Lewis. (1998). Determinants of Research Productivity in Higher Education. Research in Higher Education, 39(6), 607-631.

Hanafi, Sari., \& Arvanitis, Rigas. (2014). The broken cycle : Universities, research and society in the Arab region proposals for change (p. 93 p). Lebanon National Council for Scientific Research; UN ESCWA Technology Centre.

Kleiche-Dray, M., Waast, R., \& Fehri, O. (2008). Le Maroc scientifique. 
Long, R. G., Bowers, W. P., Barnett, T., \& White, M. C. (1998). Research Productivity of Graduates in Management : Effects of Academic Origin and Academic Affiliation. Academy of Management Journal, 41(6), 704-714. https://doi.org/10.5465/256966

Pier Luigi Rossi, \& Roland Waast. (2008). La production scientifique du Maroc. Données récentes. Communication faite en séance plénière à l'Académie Hassan II des Sciences et des Techniques, IRD.

Waast, R., Rossi, P. L., \& Richard-Waast, C. (2007). Les Sciences humaines et sociales au Maghreb Essai bibliométrique. Institut de Recherche pour le Développement). https://horizon.documentation.ird.fr/exl-doc/pleins_textes/divers17-05/010069900.pdf 